\title{
Prevalence of Bovine Hydatidosis and its Economic Importance in Adama Municipal Abattoir, Eastern Ethiopia
}

\author{
Mekuria Mandefro ${ }^{1}$; Birhanu Tilahun ${ }^{1}$; Yehualashet Bayu ${ }^{1}$; and Tesfaheywet Zerye- \\ hun $^{1^{*}}$ \\ ${ }^{1}$ College of Veterinary Medicine, Haramaya University, P.O. Box-138, Dire Dawa, \\ Ethiopia \\ "Corresponding author: Email- tesfahiwotzerihun@yahoo.com
}

\begin{abstract}
Hydatidosis is a major parasitic disease condition responsible for low productivity of livestock industry in Ethiopia due to imposing poor weight gains and condemnation of organs. This study was conducted from November 2016 to April 2017 in Adama municipal abattoir to estimate the prevalence, organ distribution of the cyst, and economic importance of bovine hydatidosis. Routine meat inspection, hydatid cyst count and characterization were conducted. Out of 400 cattle slaughtered at Adama municipal abattoir, 210 (52.5\%) animals were found harboring hydatid cysts. The infection prevalence was higher in lung $105(26.2 \%)$ than the rest of the organs examined. In the present study, explanatory variables (sex, age, breed, body condition and origin) were found to have statistically significant $(\mathrm{p}<0.05)$ association with the prevalence of hydatidosis. Of the total of 970 hydatid cysts counted, 529/731(72.4\%) small, 89/100(89\%) medium, 42/45(93.3\%) large and 20/94(21.3\%) calcified cysts were detected in lung. Liver harbored 194/731(26.5\%) small, 11/100(11\%) medium, $3 / 45(6.7 \%)$ large and 74/94(78.7\%) calcified cysts. Out of 208 cysts subjected for fertility and viability testing 120(57.7\%), 74(35.6\%), 40(54\%) 34(46\%) and $14(6.7 \%)$ were sterile, fertile, viable, non-viable and calcified cysts, respectively. The financial loss due to organ condemnation annually and during the study period was estimated to be 894,505.612 ETB and 17,844.90 ETB, respectively. The prevalence of hydatidosis in such a high proportion implies that the disease is economically important in the study area. Therefore, there should be strict control of hydatidosis by focusing on backyard slaughter practice, unsafe offal feeding of dogs, and proper west disposal. Moreover, awareness creation on its zoonotic importance, route of transmission and the growing stray dog population need to be given special attention.
\end{abstract}

Keywords: Abattoir; Adama; Cattle; E. granulosus; hydatidosis 


\section{Introduction}

Cystic Echinococcosis (CE) is one of the most important and commonly found parasitic zoonoses in both humans and different animals (Sadjjadi, 2006). It is a chronic zoonotic disease condition associated to infection with the larval stage (hydatidcysts) of the dog's Echinococcus (Elmahdi, 2004). Echinococcus belong to Kingdom Animalia; Phylum Platyhelminthes; Class Cestoda;_Order Cyclophyllidea; Genus Echinococcus; Species E. granulosus. Two hosts (definitive and intermediate hosts) are involved in the completion of the life cycle of E. granulosus (Hossein et al., 2014).

Echinococcosis causes considerable economic losses and public health problems in many countries of the world including Europe, Asia, Africa, South America, Canada and Australia (Budke et al., 2006). Both cystic and alveolar Echinococcosis has been reported from many areas. However, cystic Echinococcosis is more prevalent and has been reported from all countries in the Middle East and Arabic North Africa (Rostami et al., 2010).

In Africa E. granulosus has been recognized from most countries including Ethiopia. Previous report has described the endemic occurrence of E. granulosus in dogs and livestock (Eckert et al., 2002). In North Africa an average of 600-700 cases of hydatid cyst was recorded in Algeria annually, and it is responsible for about 2000 cases of surgery each year in Tunisia. In the same country annual surgical incidence rate was 15/10000 inhabitants (Khadidja, 2011). The public health importance of Echinococcosis includes cost of hospitalization, medical and surgical fees, losses of income and productivity due to temporal incapacity to work, social consequences, due to disability and mortality (Azlaf and Dakkak, 2006).

In Ethiopia, it is the major cause of organ condemnation in most abattoirs and leads to huge economic losses from treatment costs and livestock associated production losses. Considering the economic significance caused by hydatidosis in Ethiopia, significant degrees of monetary losses were estimated at various levels in different locations. Such reported estimates indicate annual losses of 25,608 ETB (2,807.89 US\$) in Tigray (Kebede et al., 2009c); 1,791,625.89 ETB (131,737.19 US\$) in cattle slaughtered at the Hawassa municipal abattoir (Regassa et al., 2010); 473,173.75 ETB (51,883 US\$) in cattle slaughtered at the 
Debre Markos abattoir (Kebede et al., 2009d); and 52,828 ETB (5,869.8 US\$) in cattle slaughtered at the Adama abattoir (Getaw et al., 2010).

Cystic Echinococcosis is also a disease of public health importance in the country (Getachew et al., 2012). Previous studies reveal that the prevalence of bovine hydatidiosis in cattle slaughtered in Adama municipal abattoir was 6.6\% (Yemane, 1990), 46.8\% (Getaw et al., 2010). It would be essential to have information on the current status of hydatidosis to forward pertinent recommendations. Hence, the aim of this study was to estimate the prevalence, organ distribution of the cyst, and economic importance of bovine hydatidosis in the study area.

\section{Materials and Methods}

\section{Study area}

The study was conducted in Adama municipal abattoir from November 2016 to April 2017. Adama is situated $84 \mathrm{~km}$ east of Addis Ababa (the capital city of Ethiopia) in Oromia Regional State at a latitude of $8^{\circ} 35^{\prime} 00^{\prime \prime}-8^{\circ} 36^{\prime} 00^{\prime \prime}$ north and a longitude $39^{\circ} 11^{\prime} 57^{\prime \prime}-39^{\circ} 21^{\prime} 15^{\prime \prime}$ east on the escarpment of the Great Rift Valley. The town has an area of $169.9 \mathrm{~km}$ square and 17 kebeles (CSA, 2010; NMSA, 2016). The Adama municipal abattoir provides fresh meat for different organizations such as hotels, restaurants, University and butcheries.

\section{Study population}

The study population included all cattle brought for slaughter to Adama municipal abattoir during the study period. This population comprised of cattle of different breed, sex, age composition and originating from different districts of Adama Region, Arsi, Kereyo, Bale, Borena, Haraghe, Wolenchite, Wonji and Minjar. Number of female and exotic breed of cattle in the study population was small. During the study period (November- March) about 7700 cattle were slaughtered. The average annual slaughtered animals in the study abattoir were estimated to be 20020 . 


\section{Sample size}

The sample size was determined by using the formula given by Thrusfield (2005) with expected prevalence 46.8\% (Getaw et al., 2010), level of significance $95 \%$ and absolute precision $5 \%$.

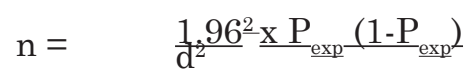

Accordingly, based on the above formula a sample size of 382 was calculated, but the total number of samples analyzed in this study were 400 .

\section{Study design and methods}

A cross-sectional study was undertaken from November 2016 to April, 2017. The survey was conducted based on randomized systematic sampling method on the bases of entrance to lairage and code numbers written on their body (cattle having similar code were identified using coat color and appearance of horn) for local breed of male cattle, and the first animal was selected by simple randomized sampling method. But since female and exotic cattle presented for slaughtering in the study area were few. They were all included in the study population regardless of systematic randomized method. Regular visit (three days per week) was made to conduct ante and post mortem examination of slaughtered cattle. In this, abattoir, an average of 120 and 20 cattle were slaughtered during every non-fasting and fasting day respectively (70 cattle per day) except Tuesday and Thursday since the next days are fasting days such as Wednesday and Friday respectively. The average number of animals sampled per day was 6 animals.

\section{Ante mortem inspection}

During ante-mortem examination, sex, breed, body condition and origin of each animal were recorded. The body condition of study population was classified into three main categories as poor, medium and good based on observation of muscle mass and fat cover on ribs, hip, between hooks, pins, spine and transverse processes (Nicholson and Buttrworth, 1986). The animal's age was categorized into adult (below or equal to 5 years) and old (above 5 years) based on dental eruption (Adane and Guadu, 2014). 


\section{Post mortem examination}

Postmortem examination was conducted through visual inspection, palpation and systemic incision of each visceral organ particularly the lung, liver, spleen, kidney, and heart (FAO, 2003). Total numbers of hydatid cysts were counted per infected organ and the cysts were measured using a ruler and classified as small $(<5 \mathrm{~cm})$, medium $(5-10 \mathrm{~cm})$ and large $(>10 \mathrm{~cm})$ cyst (Oostburg et al., 2000; Kebede et al., 2009). The cyst that showed sign of degeneration and calcification were not measured and categorized as calcified cyst.

\section{Cyst fertility and viability testing}

For confirmation of cyst fertility and viability, collected cysts were selected by purposive sampling and taken to Adama woreda parasitology laboratory. During selection, individual cysts were grossly examined for any evidence of degeneration and calcification and then the non- calcified cyst that was thought to have adequate hydatid fluid were selected. Contents of cyst was checked by transferring in to a sterile container and examined microscopically (40x) for the presence of protoscolices. Based on the presences or absence of protoscolices in hydatid fluid, cyst was identified and classified as fertile (if it has protoscolices) and non-fertile (if it has no protoscolices). The fertile cysts were further subjected to viability test where a sediment containing protoscolices was placed on the microscope glass slide and cover with cover slip and observed for amoeboid like peristaltic movement with (40x) objective. For clear vision, a drop of $0.1 \%$ aqueous eosin solution was added to equal volume of protoscolices in hydatid fluid on microscope slide with the principle that viable protoscolices should completely or partially exclude the dye while the dead ones take it up (Dalimi et al., 2002).

\section{Assessment of monetary loss}

To study the monetary loss, due to hydatidosis, only direct loss was considered and the calculation was based on condemned organs (liver, lungs, heart, kidney and spleen). In calculating cost of condemned edible organs, 15 different meat sellers; 2 meat inspector and 10 meat consumers were interviewed randomly to establish the unit price per organ and the average organ price was determined and this price index was used to calculate the loss (Denbarga et al., 2011). The percent involvement of each organ was considered in the calculation. The economic significance of the parasite was determined by the following formula 
set by Ogunrinade and Ogunrinade (1980). The present study didn't include indirect financial loss and loss due to the treatment of human hydatidosis.

$$
\mathrm{LOC}=\mathrm{NAS}[(\mathrm{Plu} \times \mathrm{Cplu})+(\mathrm{phr} \times \mathrm{Cphr})+(\mathrm{pli} \times \mathrm{Cpli})+(\mathrm{psp} \times \mathrm{Cpsp})+(\mathrm{pki} \times \mathrm{Cpki})]
$$

Where: $\mathrm{LOC}=$ Loss due to organ condemnation, NAS = Mean number of cattle slaughter annually, Plu $=$ Percent involvement of lung cases. Cplu $=$ Current mean retail price of lung, $\mathrm{Phr}=$ Percent involvement of heart, $\mathrm{Cphr}=\mathrm{Current}$ mean retail price of heart, $\mathrm{Pli}=$ Percent involvement of liver, $\mathrm{Cpli}=\mathrm{Current}$ mean retail price of liver, $\mathrm{Psp}=$ Percent involvement of spleen, $\mathrm{Cpsp}=\mathrm{Cur}$ rent mean retail price of spleen, Pkid $=$ Percent involvement of kidney, Cpkid $=$ Current mean retail price of kidney.

\section{Data analysis}

Data were collected and recorded in Microsoft excel 2010 spread sheet and coded accordingly. The prevalence of hydatidosis was calculated by dividing the number of hydatid positive animals with the total number of animals examined. The associations of explanatory variables (age, sex, breed, body condition scores, and origin of animals) with the disease were assessed using logistic regression. All statistical analyses were done using statistical software for social science (SPSS) version 20. Probability (P) value less than 0.05 was set as statistically significant.

\section{Results}

\section{Active abattoir survey:}

Of the 400 cattle examined during routine meat inspection at Adama Municipal Abattoir, 210(52.5\%) were found to harbor hydatid cyst. The study showed that all the explanatory variables were significantly associated $(p<0.05)$ except origin of animals ( $>0.05$ ), with the prevalence of hydatidosis (Table 1 ). The frequency of cyst varied among different origin of animals, which is highest in Kereyo followed by Wonji, Bale, Arsi and soon, respectively, even though the result was not statistically significant (Table 2). 
Table 1: The occurrence of bovine hydatidosis in Adama municipal abattoir with respect to different variables

\begin{tabular}{|c|c|c|c|c|c|c|c|c|}
\hline Variables & Categories & $\begin{array}{c}\text { Animal } \\
\text { examined }\end{array}$ & Negative & Positive & $\begin{array}{c}\text { Preva- } \\
\text { lence } \\
(\%)\end{array}$ & $\begin{array}{c}\text { p- } \\
\text { value }\end{array}$ & OR & $95 \%$ CI \\
\hline \multirow[t]{2}{*}{ Sex } & Male & 335 & 145 & 190 & $56.7 \%$ & 0.00 & 2.9 & $1.7-5.2$ \\
\hline & Female & 65 & 45 & 20 & $30.8 \%$ & & & \\
\hline \multirow[t]{2}{*}{ Age } & Adult & 149 & 105 & 44 & $29.5 \%$ & 0.00 & 4.7 & $3.0-7.2$ \\
\hline & Old & 251 & 85 & 166 & $66.1 \%$ & & & \\
\hline \multirow[t]{2}{*}{ Breed } & Local & 319 & 129 & 190 & $59.6 \%$ & 0.00 & 4.5 & $2.6-7.8$ \\
\hline & $\begin{array}{l}\text { Exotic/ } \\
\text { Cross }\end{array}$ & 81 & 61 & 20 & $24.7 \%$ & & & \\
\hline \multirow[t]{3}{*}{ BCS } & Poor & 85 & 28 & 57 & $67.1 \%$ & 0.00 & 2.3 & $1.5-3.4$ \\
\hline & Medium & 150 & 64 & 86 & $57.3 \%$ & & & \\
\hline & Good & 165 & 98 & 67 & $40.6 \%$ & & & \\
\hline \multirow[t]{9}{*}{ Origin } & Adama & 151 & 90 & 61 & $40.4 \%$ & 0.43 & 0.9 & $0.9-1.1$ \\
\hline & Arsi & 63 & 21 & 42 & $66.7 \%$ & & & \\
\hline & Kereyo & 43 & 11 & 32 & $74.4 \%$ & & & \\
\hline & Wonji & 42 & 12 & 30 & $71.4 \%$ & & & \\
\hline & Bale & 33 & 10 & 23 & $69.7 \%$ & & & \\
\hline & Harar & 22 & 13 & 9 & $40.9 \%$ & & & \\
\hline & Minjar & 16 & 10 & 6 & $37.5 \%$ & & & \\
\hline & Borena & 16 & 12 & 4 & $25 \%$ & & & \\
\hline & Wolnchit & 14 & 11 & 3 & $21.4 \%$ & & & \\
\hline Total & Total & 400 & 190 & 210 & $52.5 \%$ & & & \\
\hline
\end{tabular}


The present study showed that the infection was higher in lung only $(26.2 \%)$, followed by lung and liver together (15.2\%) and liver only (9.2\%), while the rest organs harbored lower frequency of cyst (table 2).

Table 2: Proportion of the infection per organs of the study animals in Adama municipal abattoir

\begin{tabular}{lccc}
\hline Organ affected & Frequency & Valid percent & $\begin{array}{c}\text { Cumulative } \\
\text { percent }\end{array}$ \\
\hline Lung only & 105 & 26.2 & 73.8 \\
Liver only & 37 & 9.2 & 83 \\
Lung and liver & 61 & 15.2 & 98.2 \\
Liver and heart & 1 & 0.2 & 98.5 \\
Lung and kidney & 2 & 0.5 & 99.0 \\
Lung, liver and kidney & 1 & 0.2 & 99.2 \\
Lung, liver and spleen & 3 & 0.8 & 100.0 \\
Total & 400 & 100.0 & \\
\hline
\end{tabular}

\section{Cyst characterization}

The load of the infection per animal varies from 1 up to 25 . A total of 970 cysts were counted and $70.1 \%, 29.1 \%, 0.1 \%, 0.4 \%$ and $0.3 \%$ of the total cysts were found on lung, liver, heart, kidney and spleen respectively (Table 3).

In this study, $75.36 \%$ small, $10.31 \%$ medium, $4.64 \%$ large and $9.69 \%$ calcified cyst were detected. The result revealed that small cysts represent the highest proportion, while large cysts are the least in terms of their prevalence (Table $3)$. 
Table 3: Distribution of cysts in different organs based on their size in cattle

\begin{tabular}{lcccccccc}
\hline Organ affected & \multicolumn{2}{c}{ Small cyst } & \multicolumn{2}{c}{ Medium cyst } & \multicolumn{2}{c}{ Large cyst } & \multicolumn{2}{c}{ Calcified cyst } \\
& N & \% & N & \% & N & $\%$ & N & $\%$ \\
\hline Lung & 529 & 72.4 & 89 & 89 & 42 & 93.3 & 20 & 21.3 \\
Liver & 194 & 26.5 & 11 & 11 & 3 & 6.7 & 74 & 78.7 \\
Heart & 1 & 0.1 & 0 & 0 & 0 & 0 & 0 & 0 \\
Kidney & 4 & 0.6 & 0 & 0 & 0 & 0 & 0 & 0 \\
Spleen & 3 & 0.4 & 0 & 0 & 0 & 0 & 0 & 0 \\
Total & 731 & 100 & 100 & 100 & 45 & 100 & 94 & 100 \\
\hline
\end{tabular}

\section{Fertility and viability study}

From the total 208 hydatid cyst collected at the abattoir during postmortem examination and subjected to sterility testing, 74(35.6\%), 120(57.7\%) and 14(6.7\%) were found to be fertile, sterile and calcified respectively. Viability testing revealed that of the total fertile cyst, 40(54.05\%) were viable and 34(45.95\%) were non-viable (Table 4).

Table 4: Distribution of cyst in lung and liver in cattle based on fertility and viability

\begin{tabular}{lccccc}
\hline \multirow{2}{*}{ Organ } & Sterility testing & \multicolumn{3}{c}{ Viability testing } \\
\cline { 2 - 5 } & Sterile & Fertile & Calcified & Viable & Non-viable \\
\hline Lung & $93(65.5 \%)$ & $44(31 \%)$ & $5(3.5 \%)$ & $28(63.6 \%)$ & $16(36.4 \%)$ \\
Liver & $27(540.9 \%)$ & $30(45.5 \%)$ & $9(13.6 \%)$ & $12(40 \%)$ & $18(60 \%)$ \\
Total & $120(57.7 \%)$ & $74(35.6 \%)$ & $14(6.7 \%)$ & $40(54.1 \%)$ & $34(45.9 \%)$ \\
\hline
\end{tabular}

\section{Financial loss assessment}

The direct financial loss was analyzed based on the information obtained during post mortem examination and interview. The 210 infected organ cattle imposed an estimated total loss of 17,844.90 ETB in the study abattoir during the study period. Accordingly, the annual loss due to organ condemnation was calculated to be 894,505.612 ETB (Table 5). 
Table 5: Number of condemned, percent involvement and average unit price of organs in cattle during the study period

\begin{tabular}{lccc}
\hline $\begin{array}{l}\text { Organs } \\
\text { inspected }\end{array}$ & $\begin{array}{l}\text { No of organs } \\
\text { condemned }\end{array}$ & $\begin{array}{l}\text { Percent } \\
\text { involvement of } \\
\text { organ }\end{array}$ & $\begin{array}{l}\text { Average unit } \\
\text { price }\end{array}$ \\
\hline Lung & 173 & $43.3 \%$ & 15 \\
Liver & 102 & $25.5 \%$ & 146.7 \\
Kidney & 3 & $0.8 \%$ & 75.4 \\
Heart & 1 & $0.3 \%$ & 39.3 \\
Spleen & 3 & $0.8 \%$ & 7 \\
Total & 282 & $70.5 \%$ & 283.4 \\
\hline
\end{tabular}

\section{Discussion}

The overall prevalence of hydatidosis in cattle slaughtered in Adama municipal abattoir during the study period was $52.5 \%$. The current finding is in close agreement with that reported 52.69\% in Hawassa (Regassa et al., 2010), 53.5\% in Assela (Ararso, 1997), and 54.8\% in Arsi region (Alemayahu, 1990). The present finding was higher than the previous works reported from in different part of the country ranging from $11.26 \%$ to $48.9 \%$ (Berhe, 2009; Kebede et al., 2009a; Kebede et al., 2009b; Terefe et al., 2012; Bekele et al., 2013; Adane and Guadu, 2014; Nasr and Mahendra, 2016). However, the current finding is lower than prevalence study in other areas like 57.6\% in Assela (Gadisa and Addis, 2016), and 62.96\% around Bale (Polydorou, 1981). These discrepancies in disease prevalence among the various studies in different areas might be due to the difference in availability and frequency of exposure of the final hosts among the infected intermediate hosts and vice-versa.

In the present study the variables such as, sex, age, breed, body condition showed statistical significant $(p<0.05)$ association whereas origin of the animals was statistically insignificant $(\mathrm{p}>0.05)$ with the prevalence of hydatidosis during the study period. In the present study male animals were highly affected (56.7\%) than females (30.8\%). This difference in the infection rate could mainly be due to the fact that most females came from the farm (intensive) which decreases the contact rate with the definitive host and contaminated pasture. However, the current finding disagrees with what was reported from Harar (Lemma et al., 2014) where infection rate was high in female (14.5\%) than 
male (9.1\%). With regard to age the infection rate was higher in cattle having age older than 5 years $(66.1 \%)$ than in cattle having age $\leq 5$ years $(29.5 \%)$. This finding was in agreement with the study in Gonder ELFORA abattoir carried out by Adane and Guadu (2014). This might be due to longer exposure time to $E$. grannulosus eggs in addition to weaker immunity against the infection in older animals. In addition, most of the older animals slaughtered were culled animals due to less productivity and hence were exposed to the disease over long period with an increased possibility of acquiring the infections.

In the current study the infection rate was higher in local (59.6\%) than exotic/ cross breed (24.7\%) cattle. This finding disagreed with the finding in Harar (Lemma et al., 2014). The lower infection rate in the present study might be due to the reason that most of the exotic/cross breeds came to the study abattoir from the intensive type of farming system contributing to lower chance of contact with the definitive host. In the present study, the infection rate of bovine hydatidosis was higher in animals having poor body condition than medium and in medium than in good body conditioned animals. This finding supported the study in Gonder by Adane and Guadu (2014). With respect to the origin of the slaughtered animals, though the result indicates that prevalence of the disease was higher in Kereyo and lowest in Wolenchite, it was statistically insignificant (Table1). This may be due to difficulty in getting exact origin of the animals and exchanging of the animals in local markets. This result is inconsistent with the result of Yetnayet (2010), who reported that there is significant association between bovine hydatidosis and animal origin which could be due to difference in social activity, attitude to dogs and climate in different regions.

In the present study the highest infection rate occurred in the lung only followed by lung and liver than other organs examined during the study period. This finding disagrees with the study in Dire Dawa (Mulatu et al., 2013). But it agrees with the study in Jimma municipal abattoir (Tolosa et al., 2009) and in Sebeta (Mekuria and Hirpassa, 2015). This high infection rate in lung may be due to the possibility of the hexacanth embryo to enter the lymphatic circulation and be carried via the thoracic duct to the lung in such a way that the lung may be infected before/instead of the liver (Zewdu et al., 2010). On the other hand, the higher infection rate in lung and liver than the other organ may be due to the reason that liver and lung possess greater capillaries that act as partial barrier for the ingested hexachant/onchospher embryos taking the portal 
vein route and primarily affect the hepatic and pulmonary system sequentially before any other peripheral organ invasion (Esatgil and Tuzer, 2007).

In the present study, lung has higher number of cyst than liver; and liver than the other organs. This finding is nearly close to the findings of Fikre (1994) and Nebiyou (1990). Such variation in cyst abundances in an organ is explained as probably to the special distribution and infectivity of Echinococcus eggs (Gemmel, 1979). In connection with the cyst size, the proportion of small, medium and large cyst is higher in lung than liver (Table4). This finding was in line with the result of study in Kombolcha ELFORA abattoir (Abunna et al., 2012) and in Dessie (Melaku et al., 2012). Higher proportion of medium and large cysts in lung might be due to the thoracic duct through which the oncosphers reach the lung before the liver via entering the lymphatic system and the softness of the lung tissue that enable the oncosphers to easily grow to larger hydatide cyst. On the other hand, higher proportion of small cyst than medium and large might be the result of late infection due to heavy rain fall and continuous grazing in the past rainy season or due to immunological response of the hosts which may inhibit expansion of cyst size (Melaku et al., 2012). But the present study disagrees with the result of the study in Dire Dawa (Mulatu et al., 2013) whose finding showed that higher proportion of cysts was found in liver than in lung. Liver in the present finding has higher number of calcified cysts $74 / 94(78.7 \%)$ than the lung 20/94(21.3\%). This might be due to the relatively higher number of reticulo-endothelial and connective tissue reaction of the organ (Adane and Guadu, 2014).

Among cysts tested for fertility, the highest percent of cyst detected were fertile cysts followed by sterile cysts and calcified cysts. Lung was found to harbor higher percent of fertile cyst than sterile and calcified cysts, while liver also hosted the highest percent of sterile (Table: 5). This finding disagrees with the report of Mulatu et al. (2013) in Dire Dawa who found 772/968 (79.75\%) fertile,168/968(17.35 \%) sterile cysts. Likewise, Mohammed et al (2014) in Dire Dawa reported that $92(58.88 \%)$ and $33(21.15 \%)$ were fertile and sterile, respectively; while Lemma et al (2014) in study carried out in Harar showed that high proportion of cysts were fertile. This difference in fertility rate between different organs might be due to the difference in the effect of drug on the parasite among different organ in different geographical area. The viability test revealed that out of the $74 \mathrm{cysts}$, liver has $12(40 \%)$ and $18(60 \%)$ while lung has $28(63.6 \%)$ and $16(36.4 \%)$ viable and non-viable cysts, respectively. Therefore, 
more of lung's fertile cysts were viable but more of liver's fertile cysts were nonviable. This variation might be due to the difference between tissue resistances of organs for the growth of the cyst. This also might be due to the difference in action of drugs in the two organs. This finding agrees with the study in Debra Tabor Municipal Abattoir (Tadesse et al., 2016).

The direct financial loss in Adama municipal abattoir due to organ condemnation during the study period was $17844.90 \mathrm{ETB}$ and the annual financial loss was estimated to be 894505.612 ETB. This finding was much greater than the finding in Dire Dawa (Mulatu et al., 2013) (165876 ETB), Nekemte (Moje and Degefa, 2014) (8561.61 ETB) and Harar (Lemma et al., 2014) (96315.00 ETB). The figure for the financial loss due to organ condemnation in the present study is very high for the country that goes through economic transformation plan.

\section{Conclusion}

In conclusion, the present study showed that the prevalence and the estimated direct financial loss due to organ condemnation of bovine hydatidosis were high. It was also evident that lung and liver were the two organs with the highest cyst distribution compared to other organs which potentially leads to higher rate of condemnation of these organs. Therefore, control of the parasite directed both in the intermediate and definitive host should be carried out. Additionally, aggressive meat inspection, proper disposal of affected organs and deworming of dogs in the study area should be carried out.

\section{Acknowledgements}

The authors would like to thank the meat inspectors at Adama Municipal Abattoir and laboratory workers at the Adama woreda parasitology laboratory who rendered technical assistance during the study.

\section{Conflict of interest}

There is no conflict of interest to declare 


\section{References}

Abunna, F., Fentaye, S., Megersa, B., Regassa, A.,2012. Prevalence of bovine hydatidosis in Kombolcha ELFORA abattoir, North Eastern Ethiopia. Open J. Ani. Sci.,2(4), 281-286. 0913386721. http://dx.doi.org/10.4236/ojas.2012.24038.

Adane, M., and Guadu, T., 2014. Bovine Hydatidosis: Occurrence, Economic and Public Health Importance in Gondar ELFORA Abattoir. Euro. J. App. Sci.,6 (2), 11-19. DOI: 10.5829/idosi.ejas.2014.6.2.8585.

Alemayehu, L., 1990. Prevalence of hydatidosis in cattle, sheep, goats and Echinococcosis in Dogs in Arsi. DVM thesis, Faculty of Veterinary Medicine, Debrezeit Ethiopia. Pp. 26.

Ararso, O. (1997): The prevalence of hydatidosis in and around Assela. DVM Thesis, Faculty of Veterinary Medicine Addis Ababa University, Debrezeit, Ethiopia.

Azlaf, R. and Dakkak, A., 2006. Epidemiological study of the cystic echinococcosis in Morocco. Vet. Parasitol., 137, 83-93.

Bekele, J., Kebede, W., Shimelis, S., Shiferaw, D.,2013. Prevalence and financial loss estimation of cystic echinoccocosis in cattle slaughtered at Mizan Teferi and Teppi municipal abattoir south western Ethiopia. Euro. J. App. Sci.,5(1), 12-18. DOI: 10.5829/idosi.ejas.2013.5.1.66102.

Berhe, G., 2009. Abattoir survey on cattle hydatidosis in Tigray region of Ethiopia. Trop. Anim. Hlth. Prod., 41, 1347-1352. doi: 10.1007/s11250-009-9320-0.

Budke, M., Deplazes, P., and Torgerson, R., 2006. Global socioeconomic impact of cystic echinococcosis. Emerg. Inf. Dis.,12(2), 296-303. doi: 10.3201/eid1202.050499.

CSA (2010). Central Statistical Agency Federal Republic Democratic of Ethiopia Agricultural Sample Survey 2008/2009(2001 E.C). Report on livestock and livestock characteristics.

Dalimi, A., Motamedi, G., Hosseini, M., Mohammadian, B., Malaki, H., Ghamari, Z. and Ghaffari, F.F., 2002. Echinococcosis/Hydatidosis in western Iraq. Vet. Parasitol., 105(2), 161-171. doi.org/10.1016/S0304-4017(02)00005-5.

Denbarga, Y., Demewez, G., Sheferaw, D., 2011. Major Causes of Organ condemnation and financial significance of cattle slaughtered at Gondar Elfora Abattoir, Northern Ethiopia. Global Veterinaria, 7, 487-490.

Eckert, J., Schantz, P.M. and Gasser, B., 2002. WHO/OIE manual in echinococcosis in humans' animals. Geographic distribution and prevalence. World health Organization and World Organization for Animal Health, Paris, Pp. 101-143. 
Elmahdi, I., Ali, E., Magzoub, Q., Ibrahim, M., Saad, A. and Roming, M., 2004. Cystic echinococcosis of livestock and human in central Sudan. Ann. Trop. Med. Parasitol., 98, 473-479.

Esatgil, M.U and Tuzer, E., 2007. Prevalence of hydatidosis in slaughtered animals in Thrace, Turkey. Turkiye Parazitol. Derg., 31(1). 41-45.

FAO, 2003. Diagnostic Manual on Meat Inspection for Developing Countries, Pp. 12-38.

Fikre, L., 1994. Hydatidosis in Nekemete prevalence in slaughtered cattle sheep, estimate economic loss and incidence in stray dogs. DVM thesis, Faculty of Veterinary Medicine, Debrezeit Ethiopia.

Gadisa, B., and Addis, M., 2016. The Abattoir Prevalence and Monetary Loss of Fasciolosis and Hydatidosis among apparently Healthy Slaughtered Cattle at Asella Town, Ethiopia, World Appl. Sci. J., 34 (7): 897-904. DOI: 10.5829/idosi. wasj.2016.34.7.104144.

Gemmel, M.A.,1979. Hydatidosis control- A global view, Aus. Vet. J., 55. 118-125. https://doi.org/10.1111/j.1751-0813.1979.tb15246.x.

Getachew, D., Almaw, G., and Terefe, G., 2012. Occurrence and fertility rates of hydatid cysts in sheep and goats slaughtered at Modjo Luna Export Slaughter House, Ethiopia. Ethiop.Vet. J.,16, 83-91. http://dx.doi.org/10.4314/evj.v16i1.7.

Getaw, A., Beyene, D., Ayana, D., Megersa, B., Abunna, F., 2010. Hydatidosis: prevalence and its economic importance in ruminants slaughtered at Adama municipal abattoir, central Oromia, Ethiopia. Acta Trop.., 113, 221-225. https://doi. org/10.1016/j.actatropica.2009.10.019.

Hossein, M., Ebrahim, S., Dezaki, F., Kheirandish, B., Ezatpour, S., Jahanbakhsh, M., Fasihi, H. 2014. Scolicidal Effects of Black Cumin Seed (Nigella sativa) Essential Oil on Hydatid Cysts. Korean J. Parasitol.,52(6), 653-659. doi: 10.3347/ kjp.2014.52.6.653

Kebede, N., Tilahun, G. and Hailu, A., 2009a. Current status of bovine cysticercosis of slaughtered cattle in Addis Ababa Abattoir, Ethiopia. Trop. Anim. Hlth. Prod.,41(3), 290-294. DOI 10.1007/s11250-008-9188-4.

Kebede, N., Mitiku, A., Tilahun, G., 2009b. Hydatidosis of slaughtered animals in Bahir Dar abattoir, northwestern Ethiopia. Trop. Anim. Hlth. Prod.,41(1), 43-50. doi: 10.1007/s11250-008-9152-3.

Kebede W., Hagos, A., Girma, Z. and Lobago, F. 2009c. Echinococcosis/hydatidosis: its prevalence, economic and public health significance in Tigray region, North Ethiopia. Trop.Anim. Hlth. Prod.,41(6), 865-871. doi: 10.1007/s11250-008-9264-9. 
Kebede, N., Abuhay, A., Tilahun, G. and Wossene, A., 2009d. Financial loss estimation, prevalence and characterization of hydatidosis of cattle slaughtered at DebreMarkos municipality abattoir, Ethiopia. Trop.Anim. Hlth. Prod.,41(8), 1787-1789. doi: 10.1007/s11250-009-9356-1.

Khadidja, H., Yahia, A., Ghadiri, Y., Vasile, C., 2011. Epidemiologic study of hydatidosis in the steppe regions of Djelfa, Algeria. Sci.Parasitol.,12(4),177-183.

Lemma, B., Abera, T., Urga, B., Niguse, A., and Agonafir, A., 2014. Prevalence of Bovine Hydatidosis and Its Economic Significance in Harar Municipality Abattoir, Eastern Ethiopia. Amer.-Eurasian J. Scientific Res.,9 (5), 143-149. DOI: 10.5829/ idosi.aejsr.2014.9.5.9144.

Mekuria, S., and Hirpassa, L.,2015. Prevalence and Viability of Hydatidosis in Cattle Slaughtered at Sebeta Municipal Abattoir, Central Ethiopia. Acta Parasitol. Globalis, 6 (1), 01-07. DOI: 10.5829/idosi.apg.2015.6.1.9112.

Melaku, A., Lukas, B. and Bogale, B., 2012. Cyst Viability, Organ Distribution and Financial Losses due to Hydatidosis in Cattle Slaughtered at Dessie Municipal Abattoir, North-eastern Ethiopia, Vet. World, 5(4), 213-218.

Mohammed, A., Chanie, M., and Warsame, I., 2014. Prevalence, Economic and Public Health Significance of Camel Hydatidosis in Dire Dawa Municipal Abattoir, Eastern Ethiopia. Acta Parasitol. Globalis. 5 (2): 98-106. DOI: 10.5829/idosi. apg.2014.5.2.84209.

Moje, N., and Degefa, A.,2014. Prevalence, cyst viability, organ distribution and financial losses due to hydatidosis in cattle slaughtered at Nekemte municipal abattoir, western Ethiopia. J.Vet. Med.Anim. Hlth.,6(11), 280-288. DOI: 10.5897/ JVMAH2014.0316.

Mulatu, M., Mekonnen, B., Tassew, H., Kumar, A., 2013. Bovine Hydatidosis in Eastern Part of Ethiopia, Momona Ethiop. J. Sci., 5(1),107-114.

Nasr, W., and Mahendra, P., 2016. Prevalence, cyst viability, fertility and economic significance of bovine hydatidosis in an abattoir at Kombolcha, Ethiopia. Haryana Vet., 55 (1), 17-22.

Nebiyou, G., 1990. Hydatidosis/Echinococcosis in cattle slaughtered at Bahir-dar Municipality slaughter house. DVM thesis, Faculty of Veterinary Medicine, Debrezeit, Ethiopia.

NMSA., 2016. National Meteorology Service Agency, 2015/2016, Addis Ababa, Ethiopia.

Nicholson, M. and Buttrworth, M., 1986. A guide condition scoring of Zebu cattle international livestock center for Africa (ILCA), Addis Ababa, Ethiopia, p 3. 
Ogunrinade, F. and Ogunrinade, B., 1980. Economic importance of bovine fascilosis in Nigeria. Trop. Anim. Hlth. Prod., 12(3), 155-160.

Oostburg, B.F., Vrede, M.A., and Bergen, A.E., 2000. The occurrence of polycystic echinococcosis in Suriname. Ann. Trop. Med. Parasitol., 94(3), 247-252. DOI: $10.1080 / 00034980050006429$.

Polydorou, K., 1981. Animal health and economics. Case study: Echinococcosis with a reference to Cyprus (Dog). Bull In. Epis. 93(5-3),981-992.

Regassa, F., Molla, A. and Bekele, J., 2010. Study on the prevalence of cystic hydatidosis and its economic significance in cattle slaughtered at Hawassa municipal abattoir. Trop. Anim. Hlth. Prod.,42(5), 977-984. doi: 10.1007/s11250-009-9517-2.

Reshid, K., 2017. A city profile performer with municipal service office of Adama unpublished document, Pp. 14-16.

Rostami, N., Nazemal, M., Hosseini, M., Fasihi, E. and Harandi, M., 2010. Echinococcosis: based on molecular studie s in Iran. Gastroenterol. Hepatol. Bed Bench, $3,169-176$.

Sadjjadi, S.M., 2006. Present situation of Echinococcosis in the Middle East and Arabic North Africa. Parasitol. Int., 55, 197- 202.

SPSS., 2016. SPSS 1.0 User's Guide. USA: SPSS Inc.

Tadesse, A., Ayele, B., Asefa, A., and Haile, B., 2016. Prevalence and Economic Significance of Bovine Cystic Echinococcosis in Debra Tabor Municipal Abattoir, North West Ethiopia. Acta Parasitol. Globalis, 7 (3), 114-120. DOI: 10.5829/idosi. apg.2016.7.3.10536.

Terefe, D., Kebede, K., Beyond, D., and Wondimu, A., 2012. Prevalence and financial loss estimation of hydatidosis of cattle slaughtered at Addis Ababa abattoirs enterprise. J.Vet. Med. Anim.Hlth.,4(3), 42-47.

Thrusfield, M., 2005. Veterinary Epidemiology. $3^{\text {rd }}$ ed.y Blackwell Science Ltd, a Blackwell Publishing company, Pp. 233-236.

Tolosa, T., Tigre, W., Teka, G. and Dorny, P., 2009. Prevalence of bovine cysticercosis and hydatidosis in Jimma municipal abattoir, SouthWest Ethiopia. Onderstepoort J. Vet. Res., 76(3), 323-326.

Yemane, G. 1990. Preliminary study of echinococcosis in ruminants slaughtere at Adama Abattoir. DVM thesis, Faculty of Veterinary Medicine, Debrezeit, Ethiopia.

Yetnayet, G.,2010. Prevalence and economic significance of Bovine hydatidosis in cattle slaughtered at Gondar ELFORA abattoir, North Gondar. DVM thesis, Faculty of Veterinary Medicine, University of Gondar, Gondar, Ethiopia.

Zewdu, E., Teshome, T., Makwoya, A.,2010. Bovine Hydatidosis in Ambo Municipality Abattoir, West Shoa, Ethiopia. Ethiopia. Ethiop. Vet. J.,14 (1), 1-142.

Ethiop. Vet. J., 2019, 23 (1), 24-41 